\title{
Effect of Surface Friction on Tire-Pavement Contact Stresses during Vehicle Maneuvering
}

\author{
Hao Wang ${ }^{1}$, Imad L. Al-Qadi ${ }^{2}$, and Ilinca Stanciulescu ${ }^{3}$
}

\begin{abstract}
Accurate modeling of tire-pavement contact behavior plays an important role in the analysis of pavement performance and vehicle stability control. A threedimensional (3-D) tire-pavement interaction model was developed using the finite element method (FEM) to analyze the forces and contact stresses generated during vehicle maneuvering (free rolling, braking/acceleration, and cornering). A pneumatic radial-ply tire structure with rubber and reinforcement was simulated. The steady-state tire rolling process was simulated using an Arbitrary Lagrangian Eulerian (ALE) formulation. An improved friction model that considers the effect of sliding speed on friction coefficients was implemented to analyze the effects of pavement surface friction on contact stresses, friction forces, and cornering forces. The results show that the magnitudes and non-uniformity of contact stresses are affected by vehicle maneuvering conditions. As the pavement surface friction increases, the tangential tire-pavement

\footnotetext{
${ }^{1}$ Assistant Professor, Rutgers, The State University of New Jersey, NJ, 08854, hwang.cee@rutgers.edu

${ }^{2}$ Founder Professor of Engineering, Director, Illinois Center for Transportation, University of Illinois at Urbana-Champaign, IL, 61801, alqadi@illinois.edu

${ }^{3}$ Assistant Professor, Rice University, TX, 61801, ilinca@rice.edu
} 
contact stresses at various rolling conditions (free rolling, braking/acceleration, and cornering) and the vertical contact stresses at the cornering condition increase. It is reasonable to use the constant friction coefficient when predicting tire-pavement contact stresses at the free rolling condition or at the cornering condition with small slip angles. However, it is important to use the sliding-velocity-dependent friction model when predicting the friction force at tire braking.

Keywords: tire-pavement contact; friction; vehicle maneuvering; sliding speed; finite element method 


\section{Introduction}

Tire-pavement contact plays an important role in vehicle stability control because ground forces are transmitted to the vehicle through tires, especially at vehicle maneuvering conditions (Wong 1993, Pacejka 2006). In addition, tire-pavement contact stresses can cause complex stress-states near the pavement surface that can lead to load-induced pavement damages (Wang and Al-Qadi 2009; 2010). Therefore, accurate modeling of tire-pavement contact (i.e., distribution of contact forces and tractions at the interface) is important for both vehicle dynamics and pavement performance analysis.

The original work on contact mechanics was conducted by Hertz (1883). According to Hertz contact theory, the localized stresses that develop as two curved surfaces come in contact are dependent on the normal contact force, the radius of curvature of both bodies, and the elastic modulus of both bodies. However, several differences exist between the assumptions of Hertz's contact theory and the real tirepavement contact. These differences include the following: 1) the tire is pneumatic (hollow) with pressurized inner surface rather than solid; 2) the tire is a composite structure consisting of soft rubber and stiff reinforcement; 3) the contact surface is not frictionless, and the tire tread, composed of ribs and grooves, is not continuous. Therefore, a more advanced contact model is needed to simulate the tire-pavement contact behavior.

Large deformation, transient contact conditions, and structural complexity of the tire, are some of the challenges in modeling the tire-pavement interaction via a two-solid contact mechanics approach. Thus, it is difficult to solve the tire-pavement contact problem analytically, hence, numerical methods are necessary. The finite element method 
(FEM) is the method of choice to address the many important aspects of tire-pavement rolling contact, such as: the composite tire structure (rubber and reinforcement), the nonlinear behavior of tire and pavement material, complex boundary conditions, and temperature effects.

The transient contact with nonlinear frictional behavior at the tire-pavement interface makes the rolling contact problem more difficult than it may appear at first glance. The nonlinear frictional contact could introduce numerical difficulties into the FEM solution because the contact area and the distribution of contact tractions are not known beforehand (Laursen and Stanciulescu 2006). It is expected that the contact stresses are affected by the frictional behavior of the contact interfaces. The formation of slipping/adhesion zones in the contact area would change depending on the allowed maximum friction force. Field measurements have clearly shown that the friction coefficient between the tire rubber and pavement is dependent on the vehicle sliding speed (Henry 2000). Therefore, an appropriate friction model is needed to accurately capture the realistic interaction between the tire and pavement.

\section{Objective}

This research aims to develop a improved tire-pavement interaction model using finite element modeling (FEM) and analyze the contact stresses and forces during vehicle maneuvering (free rolling, braking/acceleration, and cornering). An improved friction model that considers sliding speed effect on friction coefficients was implemented into the tire-pavement interaction model. The effect of pavement surface friction on the tirepavement contact stresses in three directions (vertical, transverse, and longitudinal) was 
investigated. The tire forces generated at vehicle maneuvering conditions, i.e., the friction force versus slip ratio and the cornering force versus slip angle, were analyzed using different friction models.

\section{Development of A 3-D Pneumatic Tire Model}

Simplified 2-D tire models have been used in vehicle dynamics to predict tire performance in traction and stability control (Knothe et al. 2001). The common 2-D tire models can be divided into three main groups. The first group consists of the classical spring-damper models having a single contact point with the road surface. The second group is the tire-ring models, which have an outer contour in contact with the ground. The third group consists of parametric mathematic models, such as the Pacjeka model. These models are derived from measurements of testing tires under various conditions. However, these simplified models can not fully capture the complex structure of the tire and the nonlinear friction behavior at the tire-pavement interface. Recently, generalpurpose FE commercial software, such as ABAQUS, ANSYS, and ADINA, provide more tools to simulate tire structure and tire-pavement contact behavior with rolling contact.

Theoretically, a tire model should consider the following: 1) the composite structure (rubber and reinforcement) and the significant anisotropy caused by great differences in stiffness between the rubber and reinforcement; 2) the large deformation due to flexibility of tire carcass during contact with the pavement surface; 3) the nearincompressibility and the nonlinearity of rubber material (Wong 1993). The tire models 
commonly used for tire design purposes predict the deformation of the whole tire and the interaction of internal components (e.g., sidewall, tread, and belts).

This study is focused on the tire deformation as it relates to the contact region and the resulting contact stress distributions at the tire-pavement interface rather than the internal stress distribution in the tire. Therefore, simpler models can be employed for higher computational efficiency. Because tire manufacturers usually do not reveal information on material properties of the tire, the rubber is assumed in this study as linear elastic material with a Poisson's ratio close to 0.5. Different parts of rubber elements (sidewall, shoulder, belt rubber, and tread) are modeled having variable elastic stiffness. The reinforcements (radial ply and steel belts) are modeled as a linear elastic material with high modulus. The reinforcements were modeled as surface membrane elements with embedded rebar layers. These reinforced surface membrane elements were embedded in "host" continuum elements.

Fig. 1 shows the mesh of each tire component for the modeled radial ply tire (275/80 R22.5 truck tire) with five straight longitudinal ribs. The tire model comprises one radial ply, two steel belts, and a rubbery carcass (sidewall and tread). The outer radius of the tire is $506 \mathrm{~mm}$ and the tire height is $220 \mathrm{~mm}$. The two steel belts are oriented at $+20^{\circ}$ and $-20^{\circ}$ with respect to the hoop (circumferential) direction, while the radial ply is perpendicular to the circumferential direction of the tire. The rim is considered rigid and is in contact with the bead at the end of sidewall. To optimize computation speed and resolution, a finer mesh is chosen around the tread zone, and a coarse mesh is used in the sidewall. 
The initial elastic modulus of each tire component is based on examples from the literature (Zhang 2001; Ghoreishy et al. 2007). The elastic properties of rubber and reinforcements are calibrated to obtain deflection values close to experimental measurements provided by tire manufacturers. Sensitivity analysis showed that tire deflection is primarily affected by sidewall stiffness and the orientation of steel belts (crown angles). Good agreement was achieved between the predicted and measured deflections under various load and tire inflation pressure levels, as shown in Fig. 2.

Fig. 3 compares the predicted and measured contact lengths and contact areas as the tire is loaded using $17.8,22.3$, and $26.8-\mathrm{kN}$ loads (724-kPa tire inflation pressure). At each load level, the contact lengths are different for the middle, intermediate and edge ribs. The predicted contact lengths and contact areas are slightly greater than the measured values. A linear regression relationship is presented between predicted and measured contact lengths and contact areas; as shown in Figure 3 (a) and (b), respectively.

In the development of tire-pavement interaction model, the calibration was first performed at static conditions using the measured tire deflections, contact lengths, and areas at various load and pressure levels. Subsequently, the tire-pavement interaction was simulated at various rolling conditions and the model results were compared to the field measurements from literature (Pottinger 1985; Tielking and Roberts 1987; Wong 1993; Henry 2000; Anghelache and Moisescu 2012). The comparisons include the contact stress distributions at various rolling conditions and the relationship between friction/cornering forces and slip ratios. 


\section{Simulation of Rolling Tire-Pavement Interaction}

The tire-pavement interaction is a complicated problem, because it involves three nonlinear factors (material, geometry, and contact). First, pavement is a multi-layer structure with nonlinear material properties for each layer, and the tire is a composite structure including rubber and reinforcement. Second, when a tire is in contact with a pavement surface under a wheel load, the tire exhibits large nonlinear deformation. Third, the contact condition between the tire and the pavement surface is complex. Contact area and stresses vary with wheel load, tire inflation pressure, tire rolling condition, and interface friction condition.

In this study, the pavement is considered a non-deformable flat surface to achieve better computational efficiency and stability. This assumption is considered reasonable because the tire deformation is much greater than the pavement deflection when wheel load is applied on the tire and transmitted to the pavement surface. The relatively large deformation of the tire is taken into account using a large-displacement formulation for the consideration of geometric nonlinearity. The assumption of rigid pavement surface has been successfully used in previous research to study the contact forces and stresses at the tire-pavement interface (Tielking and Roberts 1987; Zhang 2001; Meng 2002; Ghoreishy et al. 2007); while the assumption of a rigid wheel on soft soil is usually employed in the field of terramechanics or vehicle-terrain interaction (Shoop 2001; Hambleton and Drescher 2009).

The tire rolling process was modeled using "steady-state transport analysis" in ABAQUS/Standard (ABAQUS 2007). Steady-state transport analysis utilizes implicit dynamic analysis and can consider the effect of tire inertia and the frictional effects at the 
tire-pavement interface. In the steady-state transport analysis, the Arbitrary Lagrangian Eulerian (ALE) formulation is used rather than traditional Lagrange or Eulerian formulations. The ALE uses a moving reference frame, in which rigid body rotation is described in an Eulerian formulation and the deformation is described in a Lagrange formulation (Hughes et al. 1981, Nackenhorst 2004). This kinematic description converts the steady-state moving contact problem into a pure spatially dependent simulation. Thus, a refined mesh is needed only in the contact region and the computational time can be significantly reduced. To ensure the selected mesh in the contact region (tread zone) is sufficiently refined, a spatial convergence analysis was conducted.

Rolling contact problems are highly nonlinear, and they are further complicated by the fact that the contact forces and contact patches are not known a priori. A solution to contact problems must satisfy general basic equations and equilibrium equations and boundary conditions. The popular approach to solve the contact problem is to use nonlinear optimization theory. Several approaches are used to enforce non-penetration in the normal direction, amongst which the most used are the penalty method, the Lagrange multipliers method, or the augmented Lagrangian method (Wriggers 2002).

The contact tractions between a tire and the pavement surface can be decomposed into two components: normal and tangential to the pavement surface. A penalty method is used to enforce the normal contact condition (impenetrability), and the Coulomb friction law to describe the tangential interaction between two contacting surfaces. In modeling, finite-sliding is allowed to account for the relative motion (separation or sliding) of two contacting surfaces when tire rolling is simulated. 


\section{Friction at Tire-Pavement Interface}

The development of friction force between tire rubber and a rough hard surface has two contributions that were commonly described as adhesion and hysteresis. The adhesion component is the result of interface shear and is important for a clean and smooth surface. The magnitude of adhesion component is related to the product of actual contact area and the interface shear strength. The hysteresis component is the result of damping losses and energy dissipation of the rubber excited by the surface asperities (Kummer 1966). Experimental measurements have shown that the friction force at tire-pavement interface is influenced by many factors, including vehicle factors (load, speed, slip ratio, slip angle, and camber angle), tire factors (tire type, inflation pressure, tread design, and rubber composition), surface conditions (micro- and macro-texture, and dryness/wetness), and environmental factors (temperature and contamination) (Henry 2000, Hall et al. 2006).

Savkoor (1986) found that friction of rubber polymer is closely related to its viscoelastic behavior due to the flexibility of polymer chains. He proposed a formulation that incorporated the effect of the sliding speed on the friction coefficient, as shown in Equation 1. In this equation, the friction coefficient increases with sliding velocity until a maximum value is reached at a certain speed, followed by a decrease of the friction coefficient.

$$
\mu_{s}=\mu_{0}+\left(\mu_{m}-\mu_{0}\right) \exp \left[-h^{2} \log ^{2}\left(v_{s} / v_{m}\right)\right]
$$

where $\mu_{0}$ is static friction coefficient; $\mu_{s}$ is sliding friction coefficient; $\mu_{m}$ is maximum value of $\mu_{s}$ at the sliding speed of $v_{m} ; v_{s}$ is sliding speed; and $h$ is a dimensionless parameter reflecting the width of the speed range in which friction varies significantly. 
Dorsch et al. (2002) found that the friction coefficient between rubber tire and road surface is a non-linear function of pressure, sliding speed, and temperature. The function can be formulated as a power law or as a quadratic formula, Equations 2 and 3 .

$$
\begin{gathered}
\mu=c_{0} p^{c_{1}} v_{s} c_{2} \\
\mu=c_{0} p+c_{1} p^{2}+c_{2} v_{s}+c_{3} v_{s}{ }^{2}+c_{4} p v_{s}
\end{gathered}
$$

where $\mu$ is friction coefficient, $c_{0}, c_{1}, c_{2}, c_{3}$, and $c_{4}$ are fitted model parameters, $v_{s}$ is sliding speed, and $p$ is normal pressure.

In this study, the effect of the sliding-velocity-dependent friction coefficient on the contact behavior at the tire-pavement interface is examined. The coefficient of friction (Equation 4) is modeled as an exponential function of sliding speed (Oden and Martins 1985). The equation describes a smooth transition from a static to a kinetic friction coefficient in terms of an exponential curve.

$$
\mu=\mu_{k}+\left(\mu_{s}-\mu_{k}\right) e^{-\alpha \cdot s}
$$

where $\mu_{k}$ is kinetic coefficient at the highest sliding speed; $\mu_{s}$ is static coefficient at the onset of sliding (zero sliding speed); $\alpha$ is user-defined decay coefficient; and $s$ is sliding speed.

For the contact between the rubber tire and the pavement surface, the static coefficient of friction is closely related to the surface micro-texture, while the decay coefficient is highly dependent on surface macro-texture (Henry 2000). In this study, we compare the contact stresses between the constant friction model and the sliding-velocitydependent friction model for a static coefficient of friction equal to 0.3 . This value is characteristic for a pavement surface with relatively poor micro-texture. Two different values of decay coefficients $(0.05$ and 0.5$)$ are used to represent the friction 
characteristics of pavement surface with good and poor macro-texture, respectively (Fig.

4).

\section{Tire-Pavement Contact Stresses at Various Rolling Conditions}

The analysis of tire-pavement contacts requires not only the understanding of the tire material and structure but also knowledge of vehicle operation. In free rolling, no additional driving/braking torque is applied on the tire, and the angular velocity is equal to the transport velocity divided by the free rolling radius. For a specific transport velocity, the angular velocity at the free rolling condition corresponds to the state characterized by zero longitudinal reaction forces (RF) acting on the tire from the pavement surface (Fig. 5).

During tire braking or acceleration, due to the applied braking or driving torque on the tire, the angular velocity of a tire is different from the angular velocity at the free rolling condition (Fig. 6(a)). As the tire is cornering, the cornering force (or side friction force) is induced on the tire due to the tread slip in a lateral direction when the vehicle is steering. The corenering force is parallel to the road surface and at an angle with the moving direction of the wheel. The friction between the tire and the road surface restricts the lateral movement of the tire and results in lateral deformation of the tread elements within the contact patch while the wheel is steering away from the forward direction. Therefore, a slip angle is induced between a rolling tire's actual direction of motion and the pointing direction (Fig. 6(b)).

Fig. 7 shows the predicted maximum 3-D contact stresses under each rib along the longitudinal contact length at the free rolling condition $(v=10 \mathrm{~km} / \mathrm{h}, \omega=5.6 \mathrm{rad} / \mathrm{s})$. The 
plots show that the maximum vertical and longitudinal contact stresses appear under the center rib of the tire, while the maximum transverse contact stress is under the intermediate rib of the tire. Note that the transverse contact stress increases in magnitude with lateral distance from the center of each rib and reaches its maximum at the edge of the rib. As expected, when a tire is in free rolling condition, the longitudinal contact stresses are negligible and, therefore, the tire has low rolling resistance at the free rolling condition. The distribution patterns of the predicted contact stresses are consistent with the distribution patterns of measured contact stresses (Pottinger 1985; Anghelache and Moisescu 2012).

Fig. 8 shows the predicted maximum 3-D contact stresses under each rib along the longitudinal contact length at the braking condition $(v=10 \mathrm{~km} / \mathrm{h}, \omega=3 \mathrm{rad} / \mathrm{s})$. Compared to the free rolling condition, tire braking causes negligible transverse contact stresses but similar vertical contact stresses and significant longitudinal contact stresses at the tirepavement interface. Figure 8(c) clearly shows that tire braking induces one-directional longitudinal contact stresses when a tire is sliding on a pavement surface, and these stresses are much greater than the longitudinal contact stresses at the free rolling condition. The longitudinal contact stresses on a pavement surface during braking and acceleration have similar magnitudes but opposite directions with forward stresses at braking and backward stresses at acceleration.

Fig. 9 plots the predicted maximum 3-D contact stresses under each rib along the longitudinal contact length at the cornering condition $(v=10 \mathrm{~km} / \mathrm{h}, \omega=5.6 \mathrm{rad} / \mathrm{s}$, slip angle $=1^{\circ}$ ). Similar to the free rolling condition, the longitudinal contact stresses at the cornering condition are negligible. However, tire cornering causes greater vertical and 
transverse contact stresses compared to the free rolling condition. It was found that the maximum vertical contact stress at tire cornering is under the intermediate tire rib instead of the center rib. Tire cornering results in the concentration of contact stresses shifting toward one side of the contact patch. Hence, the contact stress distribution is no longer symmetric with respect to the center plane.

\section{Effect of Pavement Surface Friction on Contact Stresses}

The effects of pavement surface friction on tire-pavement contact stresses are analyzed using different constant friction coefficients and friction models, respectively. In the analysis, the load on the tire is $17.8 \mathrm{kN}$ and the tire inflation pressure is $724 \mathrm{kPa}$. The analysis results show that the effect of rolling speed on contact stress distributions in the contact patch is insignificant, which is consistent with the experimental findings reported by previous researchers (Tielking and Roberts 1987). Table 1 summarizes the maximum contact stresses in three directions (vertical, transverse, and longitudinal) and the ratios of these maximum contact stresses at various rolling conditions $(v=10 \mathrm{~km} / \mathrm{h})$ when using different constant friction coefficients.

The results show that when the tire is free rolling or full braking, the vertical contact stresses are kept relatively constant as the friction coefficient increases. However, the tangential contact stress increases as the friction coefficient increases, especially for the transverse contact stress at the free rolling condition and the longitudinal contact stresses at the braking/acceleration condition. Tangential contact stresses develop through shear mechanisms while a tire rolls on a road surface and, therefore, depends on the friction coupling at the tire-pavement interface. When the tire is cornering, the contact 
stresses in three directions all increase as the friction coefficient increases; the increase of vertical and transverse contact stresses is more significant than the increase of the longitudinal contact stresses. This is probably because the tire deformation tends to be greater at one side of the contact patch during cornering and the allowed maximum friction force before sliding increases.

At the free rolling and cornering conditions, the ratios of tangential contact stresses relative to the vertical contact stresses are smaller than the friction coefficients. This indicates that no relative slippage occurs between the tire and the pavement. However, at full braking, longitudinal contact stresses are equal to vertical contact stresses multiplied by friction coefficient since the tire is essentially sliding on the pavement surface.

Table 2 summarizes the maximum contact stresses in three directions (vertical, transverse, and longitudinal) and the ratio of these maximum contact stresses at various rolling conditions when using different friction models $(v=10 \mathrm{~km} / \mathrm{h})$. The tire-pavement contact stresses at the free rolling condition or at the cornering condition are not affected by the sliding-velocity-dependent friction model; no slip is almost induced at the tirepavement interface when the tire is pure rolling or cornering at small slip angles. This indicates that it is reasonable to use constant static friction coefficient when predicting tire-pavement contact stresses at free rolling condition or at cornering condition with small slip angles. However, using the constant friction model may overestimate peak longitudinal contact stresses when the tire is sliding at the full braking condition, because the constant friction model cannot simulate the decay of friction coefficient as slip speed increases. 


\section{Effect of Pavement Surface Friction on Vehicle Dynamic Forces}

In vehicle dynamics, the tangential force developed at the tire-pavement interface as the vehicle is maneuvering is important for stability control. Fig. 10 plots the calculated longitudinal friction force that acts on the tire during braking at different slip ratios. The general trend shows that the friction force reaches its maximum when the slip ratio is around 10\% (critical slip ratio). When the slip ratio is lower than the critical slip ratio, the state of contact is partial slip; when the slip ratio is greater than the critical slip ratio, the state of contact is full slip. At full slip, the value of the maximum frictional force is equal to the normal force applied on the tire multiplied by the friction coefficient.

When the tire is at partial slip, the calculated friction forces are approximately the same when using the constant and the sliding-velocity-dependent friction models. However, different trends are observed at full slip. For the constant friction coefficient model, the friction force remains constant as the slip ratio is greater than the critical slip ratio. On the other hand, the friction force decreases as the slip ratio increases when the sliding-velocity-dependent friction model is used. The development trend of friction force using the slide-velocity-dependent model is more consistent with the measured skid resistance during the tire braking process (Henry 2000). Therefore, the tangential interaction between the tread tip and the road surface can be better captured using the improved friction models.

In addition, it is found that using the constant friction model can overestimate the maximum friction force at the critical slip ratio, especially at high speed. This is particularly important for the vehicles with an anti-lock braking system (ABS) because 
the brakes are controlled on and off repeatedly such that friction force is held near the peak.

Fig. 11 shows the forces that act on the tire during cornering at various slip angles. The results show that the cornering force increases approximately linearly for the first few degrees of slip angle, and then increases non-linearly to its peak value at the slip angle of around $5^{\circ}$ and then stays relatively constant. The relationship between the cornering forces and the slip angles strongly affects the directional control and stability of the vehicle. The development trend of the cornering force is consistent with the experimental results in the literature (Wong 1993).

At low slip angles, there is little to no slip in the contact area, thus the cornering force is not affected by the friction model. As the tire reaches higher slip angles, the slip occurs in the contact area where the lateral force approaches the available friction force. After the slip occurs, the global lateral force is dominated by the maximum friction force. Thus, the predicted cornering forces at high slip angles using the sliding-velocitydependent friction model are slightly smaller than those predicted using the constant friction model.

\section{Conclusions and Recommendations}

The developed tire-pavement interaction model has potential to predict the tire-pavement contact stress distributions at various rolling conditions (free rolling, braking/acceleration, and cornering). The magnitudes and non-uniformity of contact stresses are affected by vehicle maneuvering and as well as surface friction at the tirepavement interface. Compared to the free rolling condition, tire braking/acceleration 
causes reduction in transverse contact stresses but significant increase in longitudinal contact stresses at the tire-pavement interface. When the tire is cornering, both the vertical and transverse contact stresses are greater than those at the free rolling condition and the peak contact stresses shift toward one side of the contact patch.

At the free rolling and the braking/accelerating conditions, the tangential contact stresses increase as the friction coefficient increases. At the cornering condition, both the vertical and tangential contact stresses increase as the friction coefficient increases. This indicates that the proper friction coefficient is important for the accurate prediction of tire-pavement contact stresses. It is reasonable to use the constant friction model when predicting the tire-pavement contact stresses at the free rolling condition or at the cornering condition with small slip angles. However, it is important to use the slidingvelocity-dependent friction model when predicting the friction force at tire braking. The constant fiction model cannot simulate the decay of friction coefficient as the slip speed increases and thus overestimates the friction force.

Deformable road surfaces should be considered in future studies to simulate the coupled tire-pavement interaction behavior. The irregularities (texture) of pavement surfaces should also be considered. These topics would be important when detailed tirepavement interaction conditions are studied, including rolling resistance, tire wear, and noise.

\section{References}

ABAQUS (2007) ABAQUS Analysis User's Manual, Version 6.7, Habbit, Karlsson \& Sorenson, Inc. 
Anghelache G., and Moisescu, R. (2012) "Measurement of Stress Distributions in Truck Tyre Contact Patch in Real Rolling Conditions," Vehicle System Dynamics, Vol. 50, No. 12, pp.1747-1760.

Dorsch, V., Becker, A., and Vossen, L. (2002) "Enhanced Rubber Friction Model for Finite Element Simulations of Rolling Tires," Plastics Rubbers and Composites, 31(10), pp. $458-464$.

Ghoreishy, M.H.R., Malekzadeh, M., and Rahimi, H. (2007) "A Parametric Study on the Steady State Rolling Behavior of a Steel-Belted Radial Tire," Iranian Polymer Journal, 16, pp. 539-548.

Hall, J.W., Glover, L.T., Smith, K.L., Evans, L.D., Wambold, J.C., Yager, T.J., and Rado, Z. (2006) Guide for Pavement Friction, Project No. 1-43, Final Report, National Cooperative Highway Research Program, Transportation Research Board, Washington D.C.

Hambleton, J.P., and Drescher, A. (2009) "Modeling wheel-induced rutting in soils: Rolling," Journal of Terramechanics, No. 46, pp. 35-47.

Henry, J.J. (2000) Evaluation of Pavement Friction Characteristics, NCHRP Synthesis 291, Transportation Research Board, National Research Council, Washington, D.C.

Hertz, H. (1883) "Über die Verteilung der Druckkrifte in einem elastischen Kreiszylinder, "Zeitschrift für die. Mathematik und Physik 28 
Hughes, T.J.R., Liu, W.K. and Zimmermann, T.K. (1981) "Lagrangian-Eulerian Finite Element Formulation for Incompressible Viscous Flows," Computer Methods in Applied Mechanics and Engineering, 29, pp. 329-349.

Knothe, K., Wille, R. and Zastrau, B.W. (2001) "Advanced Contact Mechanics - Road and Rail," Vehicle System Dynamics, Vol. 35, Numbers 4-5, pp. 361-407.

Kummer, H. (1966) Unified Theory of Rubber and Tire Friction, Engineering Research Bulletin B-94, Pennsylvania State University.

Laursen A. and Stanciulescu, I. (2006) "An Algorithm for Incorporation of Frictional Sliding Conditions within a Steady State Rolling Framework," Communications in Numerical Methods in Engineering, No. 22, pp. 301-318.

Meng, L. (2002) Truck Tire/Pavement Interaction Analysis by the Finite Element Method, Ph.D. Dissertation, Michigan State University, USA.

Nackenhorst, U. (2004) "The ALE-Formulation of Bodies in Rolling Contact Theoretical Foundations and Finite Element Approach," Computation Methods in Applied Mechanics and Engineering, Vol. 193, pp 4299-4322.

Oden, J.T. and Martins, J.A.C. (1985) "Models and Computational Methods for Dynamic Friction Phenomena," Computer Methods in Applied Mechanics and Engineering, Vol. 52, Issues 1-3, pp. 527-634.

Pacejka, H.B. (2006) Tire and Vehicle Dynamics, Butterworth-Heinemann, 2nd Ed. 
Pottinger, M.G. (1992) "Three-Dimensional Contact Patch Stress Field of Solid and Pneumatic Tires," Tire Science and Technology, Vol. 20, No. 1, pp. 3-32.

Savkoor, A.R. (1986) “Mechanics of Sliding Friction of Elastomers," Wear, 113, pp. 3760.

Shoop, S.A. (2001) Finite Element Modeling of Tire-Terrain Interaction, Ph.D. Dissertation, University of Michigan, USA.

Tielking, J.T. and Roberts, F.L. (1987) "Tire Contact Pressure and Its Effect on Pavement Strain," Journal of Transportation Engineering, Vol. 113, No. 1, pp. 56-71.

Wong, J.Y. (1993) Theory of Ground Vehicles, John Wiley \& Sons, Inc.

Wang, H. and Al-Qadi, I.L. (2009) "Combined Effect of Moving Wheel Loading and Three-Dimensional Contact Stresses on Perpetual Pavement Responses," Transportation Research Record, No. 2095, pp. 53-61.

Wang, H. and Al-Qadi, I.L. (2010) “Evaluation of Surface-Related Pavement Damage due to Tire Braking," International Journal of Road Materials and Pavements Design, Vol. 11, No. 1, pp. 101-122.

Wriggers, P. (2002) Computational Contact Mechanics, John Wiley \& Sons Ltd.

Zhang, X. (2001) Nonlinear Finite Element Modeling and Incremental Analysis of A Composite Truck Tire Structure, Ph.D. Dissertation, Concordia University, Canada. 


\section{List of Figure Captions}

Fig. 1. Meshes of tire components

Fig. 2. Comparisons between measured and calculated tire deflections at (a) $414 \mathrm{kPa}$; (b) $552 \mathrm{kPa}$; (c) $690 \mathrm{kPa}$; and (d) $828 \mathrm{kPa}$

Fig. 3. Comparisons of predicted and measured contact (a) lengths; and (b) areas

Fig. 4. Sliding-velocity-dependent friction models used in the study

Fig. 5. Longitudinal reaction force at various angular velocities for a specific transport velocity $(v=10 \mathrm{~km} / \mathrm{h})$

Fig. 6. Illustrations of torques and forces at tire (a) braking and (b) cornering

Fig. 7. Comparison of (a) vertical, (b) transverse, and (c) longitudinal contact stress distributions at free rolling condition

Fig. 8. Comparison of (a) vertical, (b) transverse, and (c) longitudinal contact stress distributions at full braking condition

Fig. 9. Comparison of (a) vertical, (b) transverse, and (c) longitudinal contact stress distributions at cornering condition

Fig. 10. Friction forces due to tire braking using different friction models at (a) $10 \mathrm{~km} / \mathrm{h}$ and (b) $30 \mathrm{~km} / \mathrm{h}$

Fig. 11. Cornering forces using different friction models 


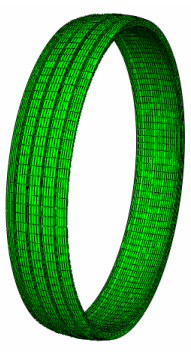

Tread rubber

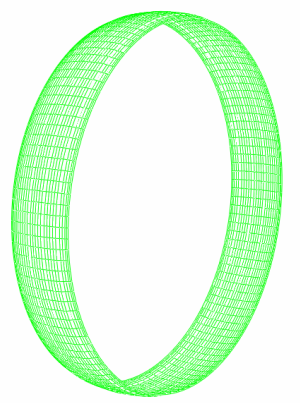

Belt layer

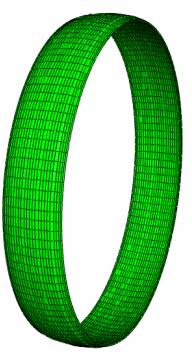

Belt rubber

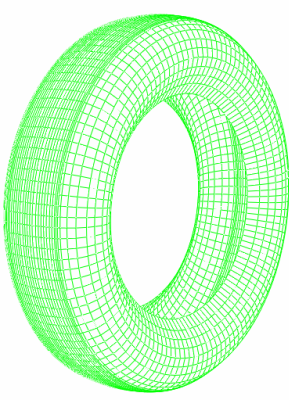

Radial ply

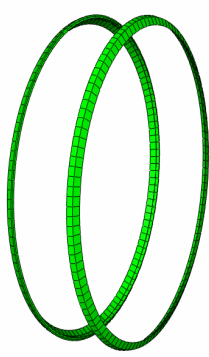

Shoulder

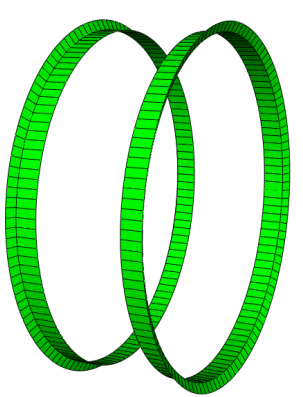

$\operatorname{Rim}$

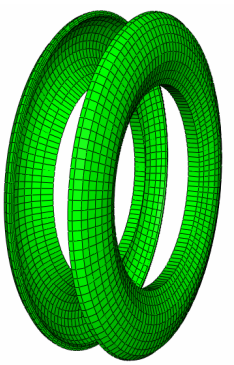

Sidewall

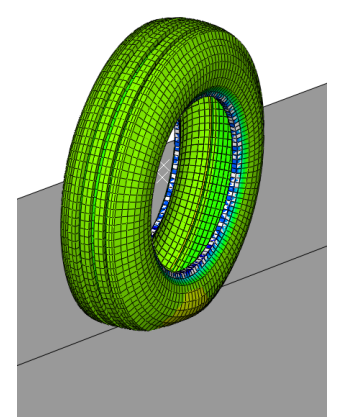

Full tire

Fig. 1. Meshes of tire components

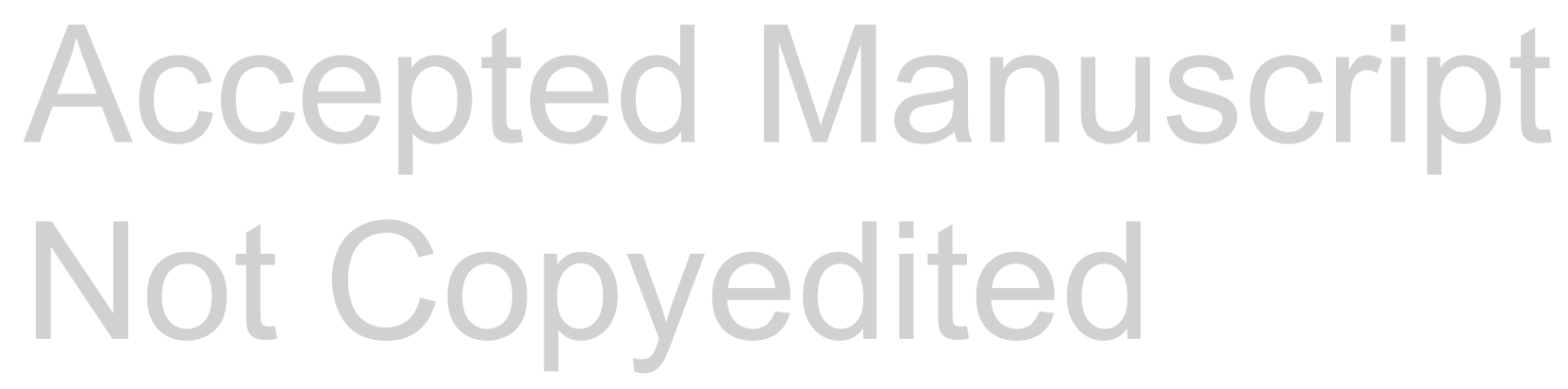




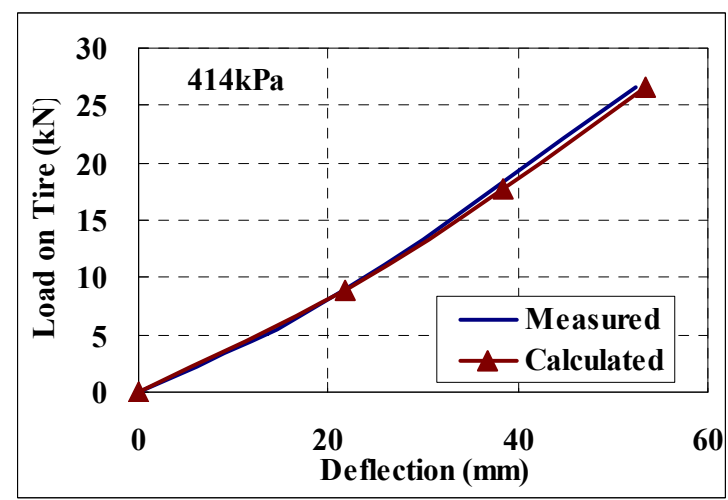

(a)

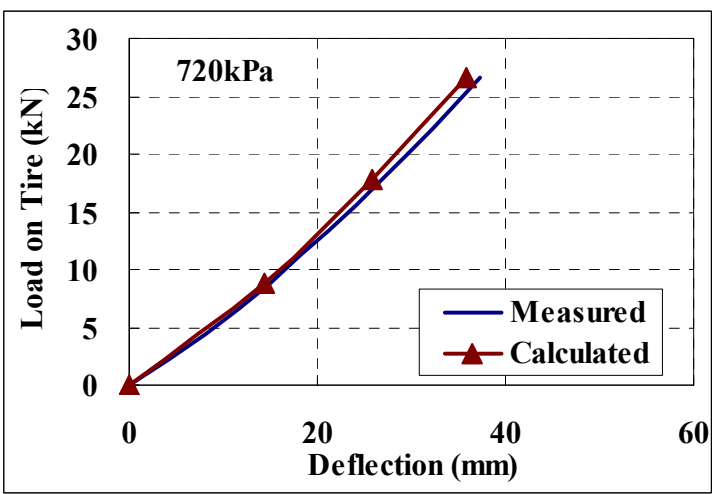

(c)

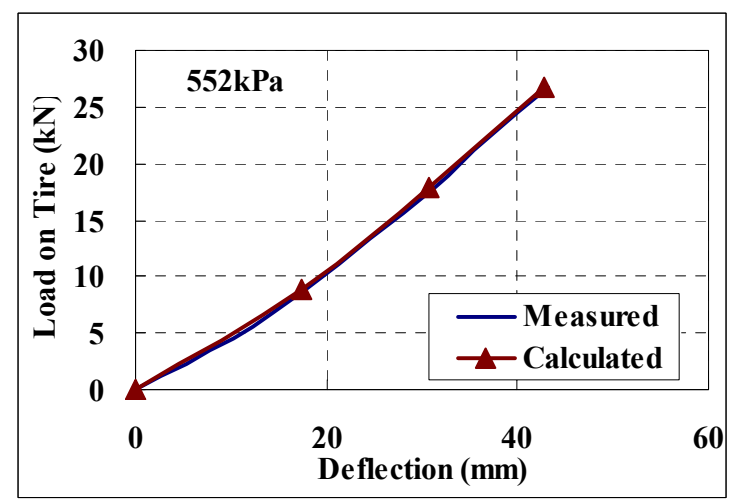

(b)

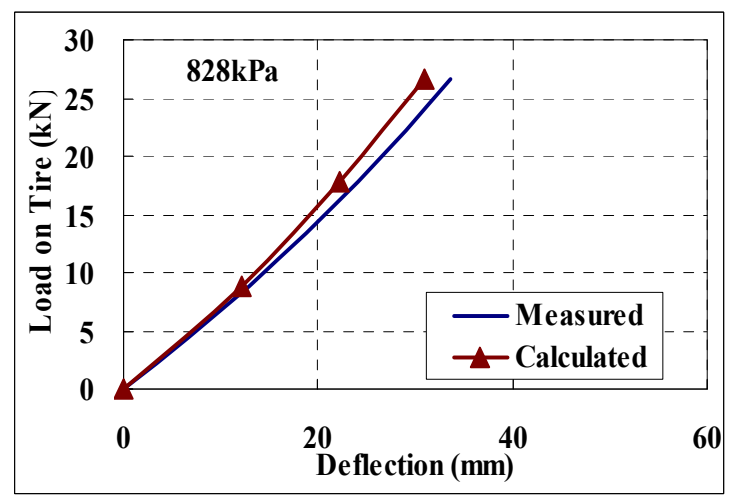

(d)

Fig. 2. Comparisons between measured and calculated tire deflections at (a) $414 \mathrm{kPa}$; (b) $552 \mathrm{kPa}$; (c) $690 \mathrm{kPa}$; and (d) $828 \mathrm{kPa}$ 

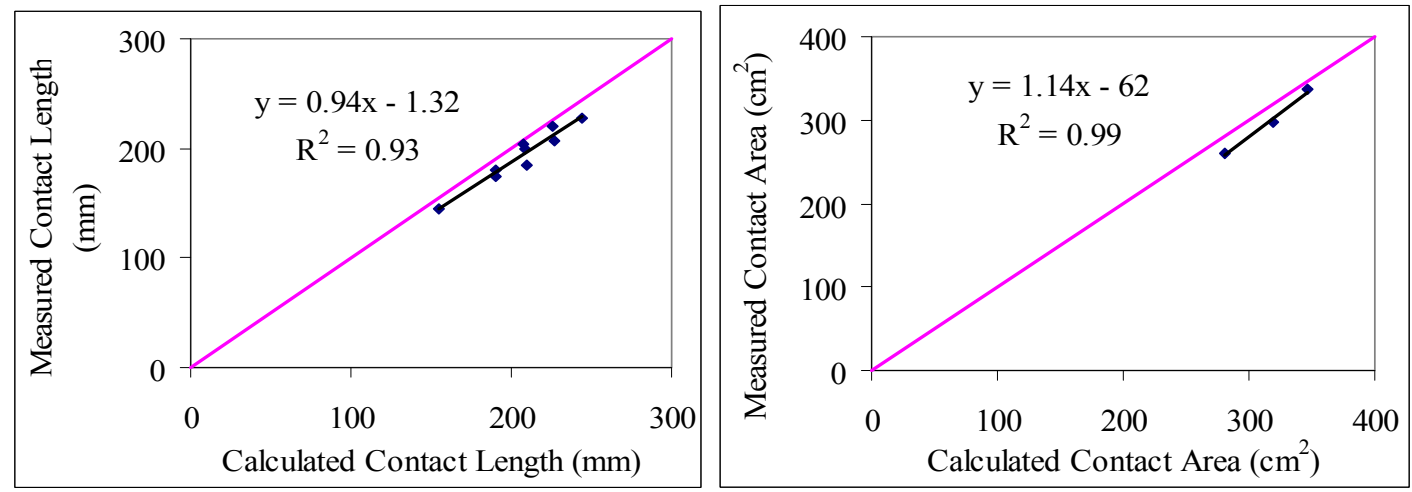

Fig. 3. Comparisons of predicted and measured contact (a) lengths; and (b) areas

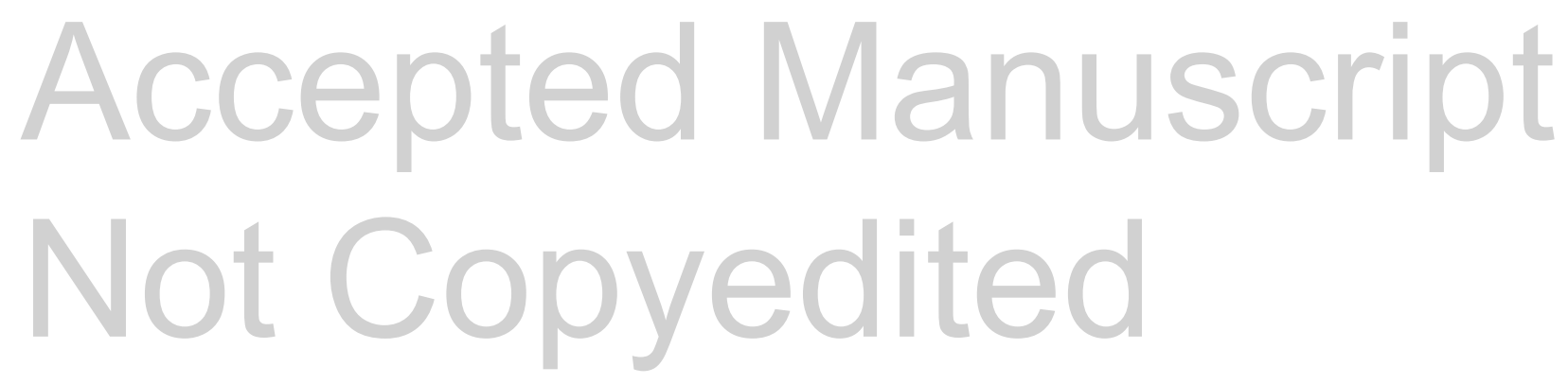




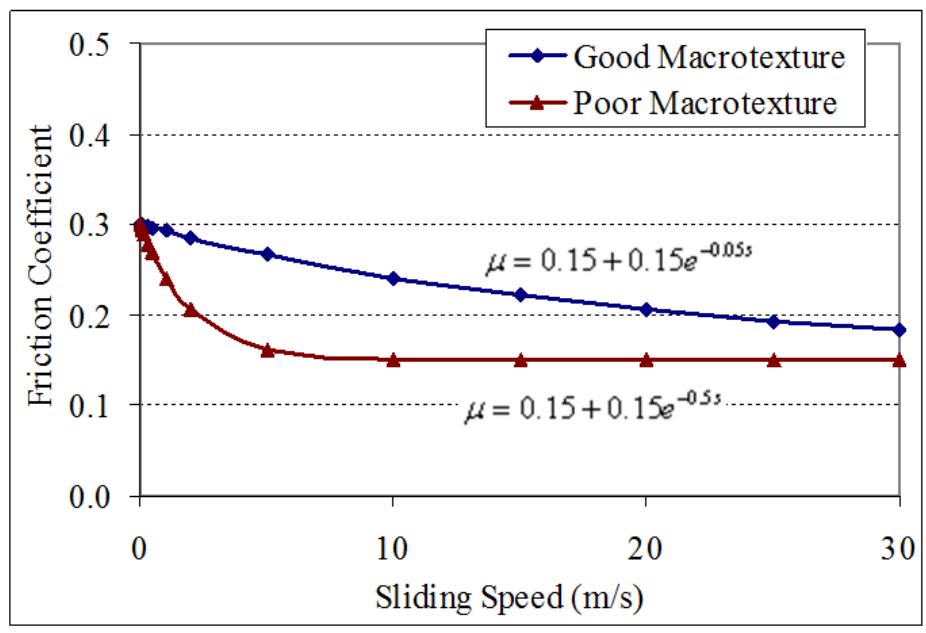

Fig. 4. Sliding-velocity-dependent friction models used in the study

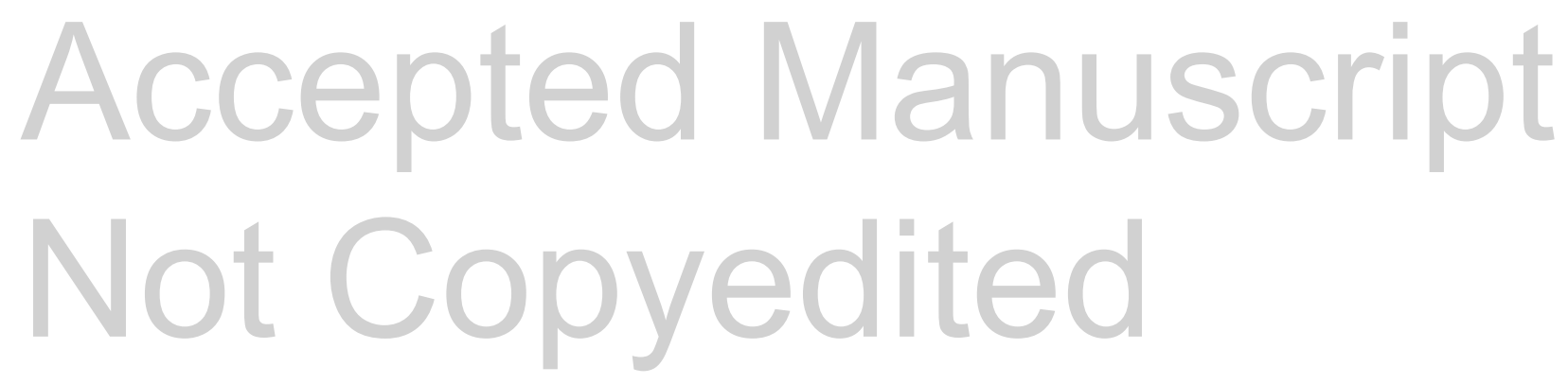




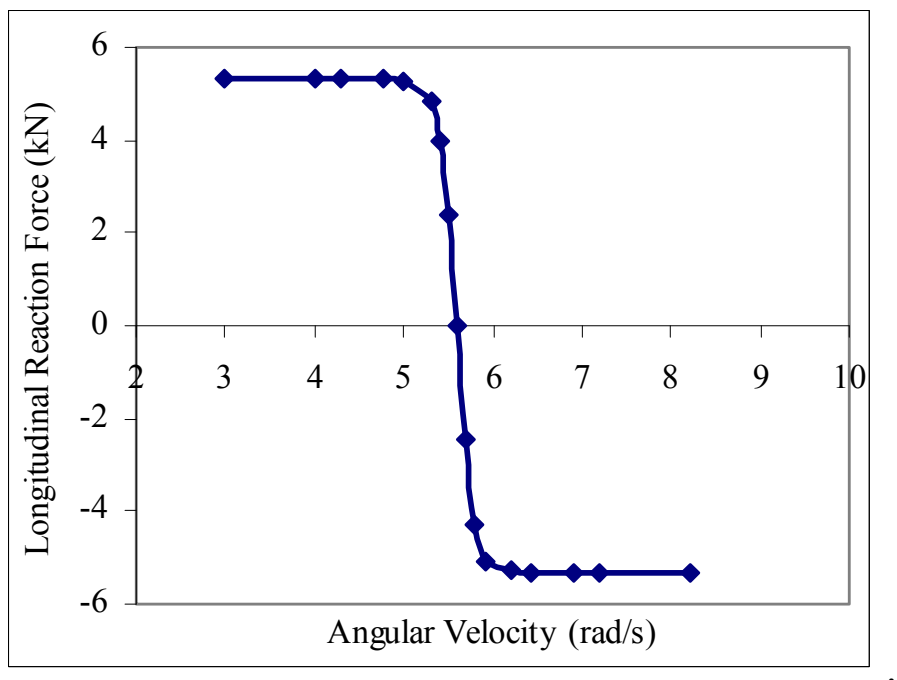

Fig. 5. Longitudinal reaction force at various angular velocities for a specific transport velocity $(v=10 \mathrm{~km} / \mathrm{h})$

\section{Accepted Manuscript Not Copyedited}




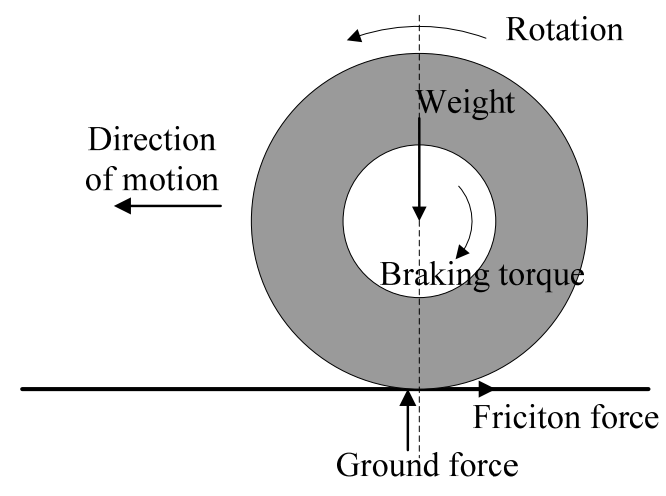

(a)

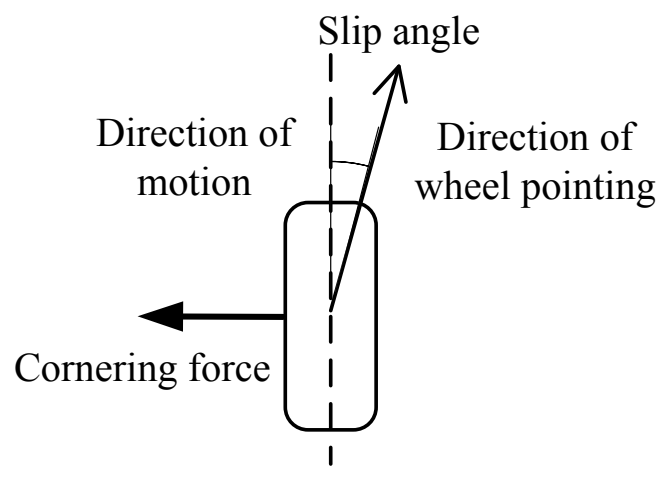

(b)

Fig. 6. Illustrations of torques and forces at tire (a) braking and (b) cornering

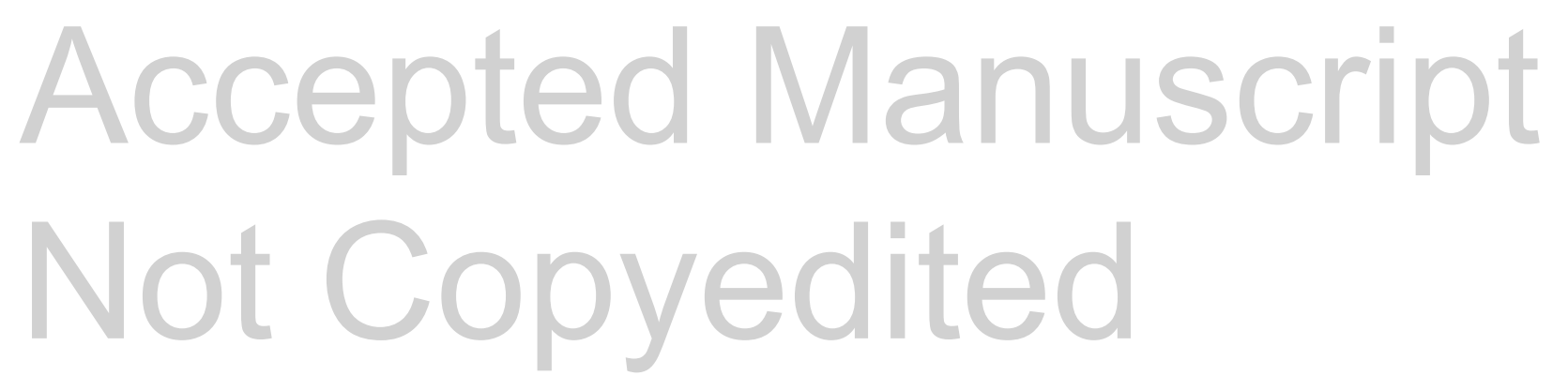




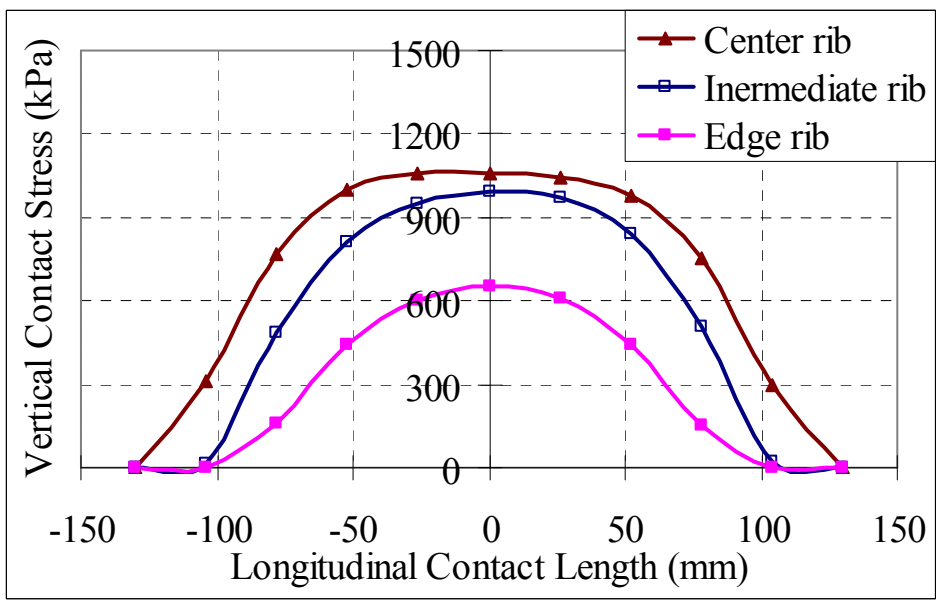

(a)

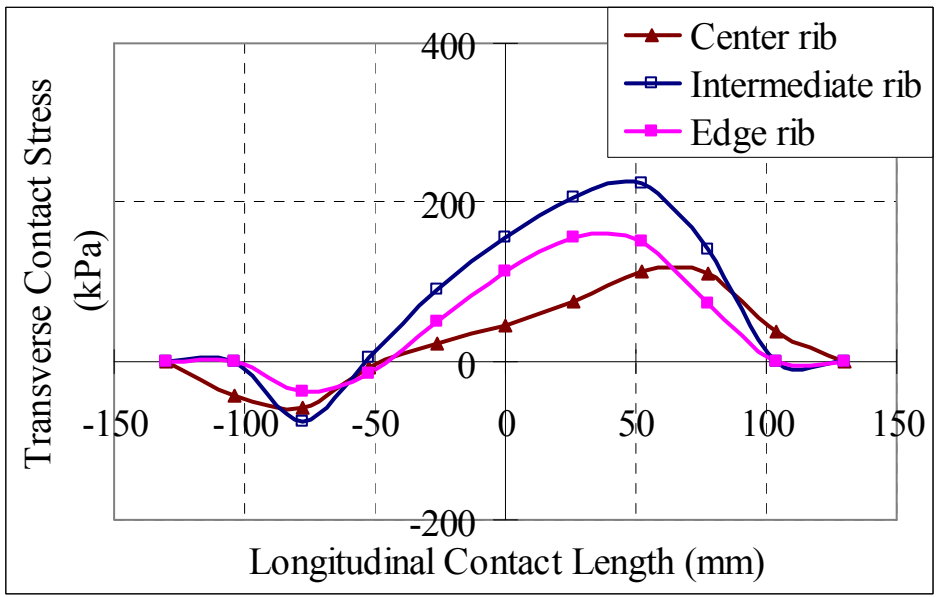

(b)

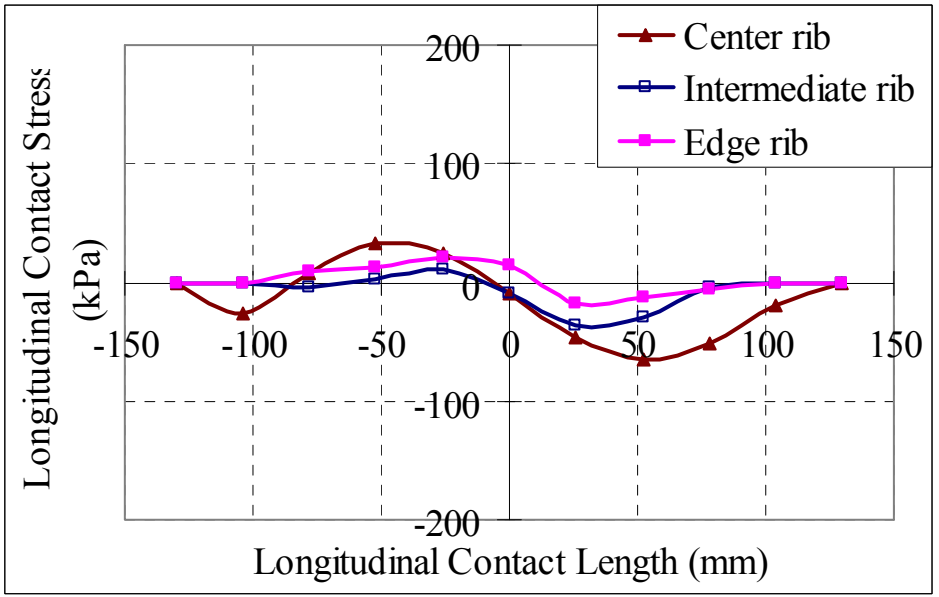

(c)

Fig. 7. Comparison of (a) vertical, (b) transverse, and (c) longitudinal contact stress distributions at free rolling condition 


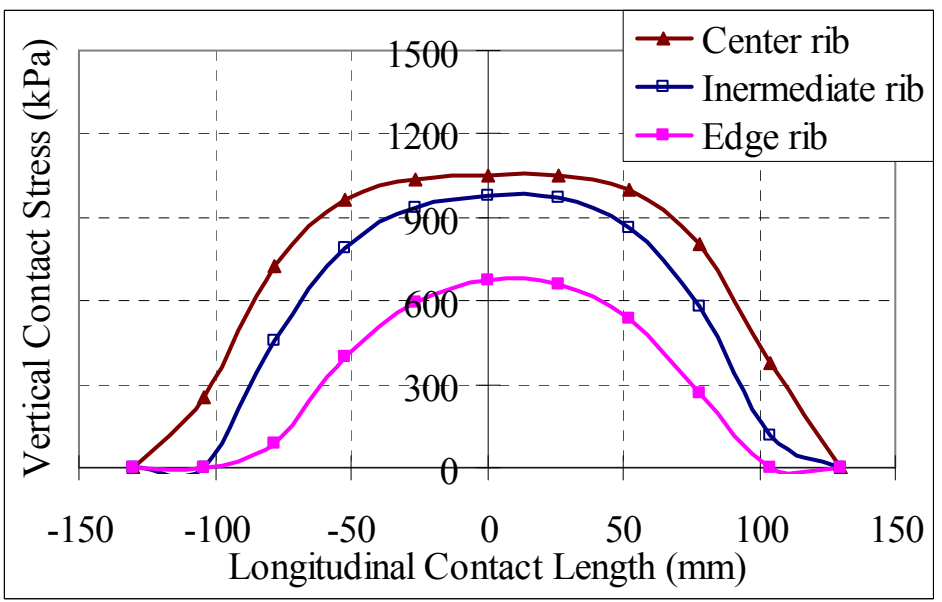

(a)

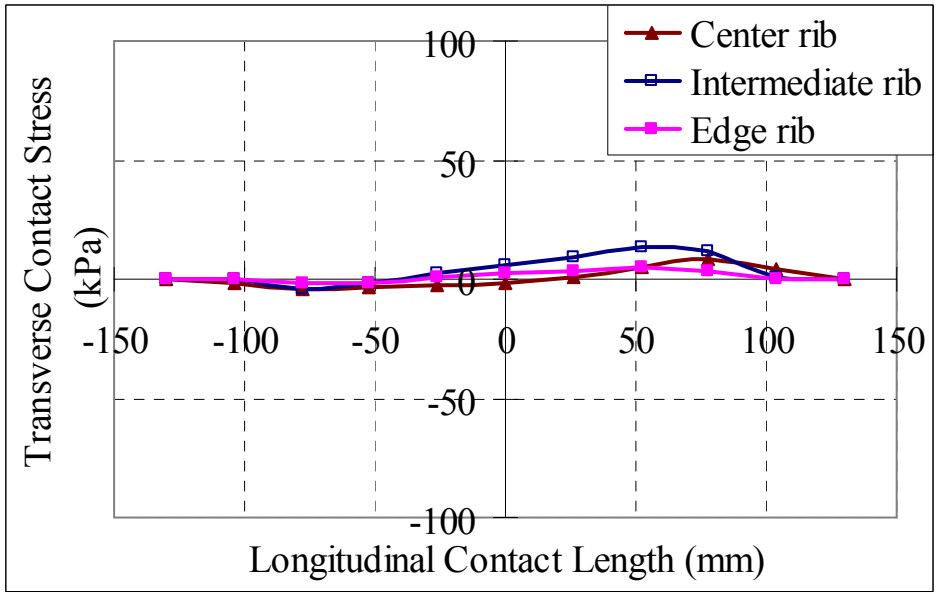

(b)

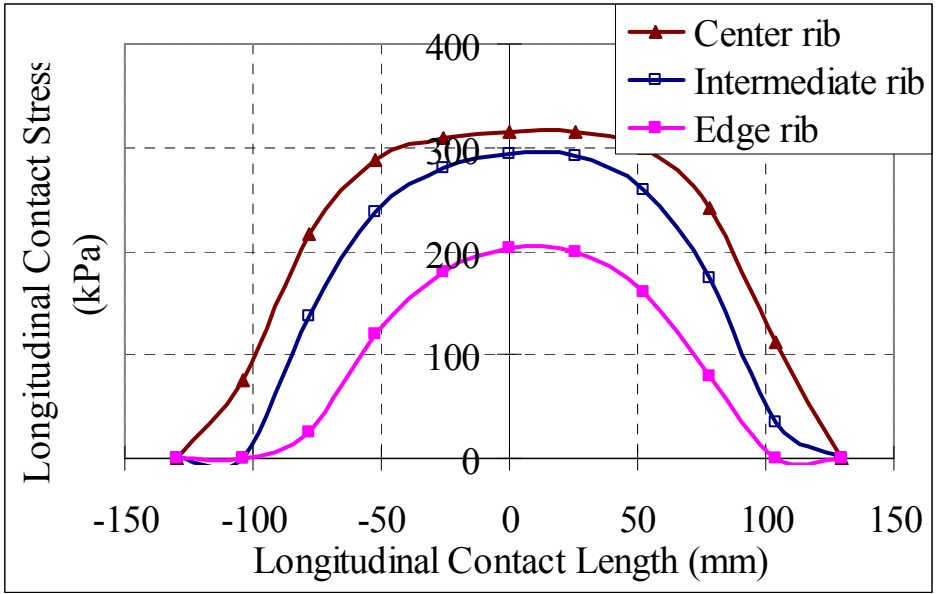

(c)

Fig. 8. Comparison of (a) vertical, (b) transverse, and (c) longitudinal contact stress distributions at full braking condition 


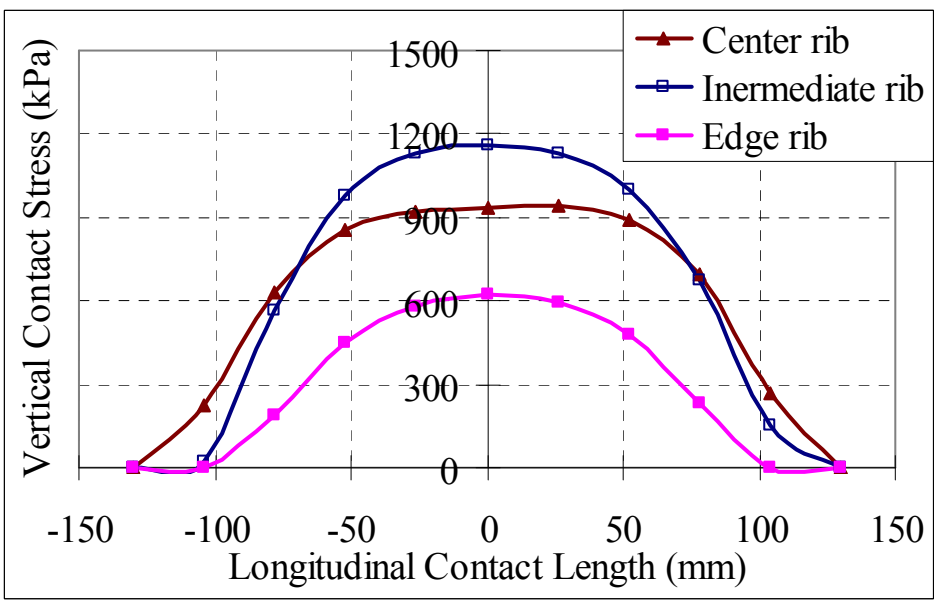

(a)

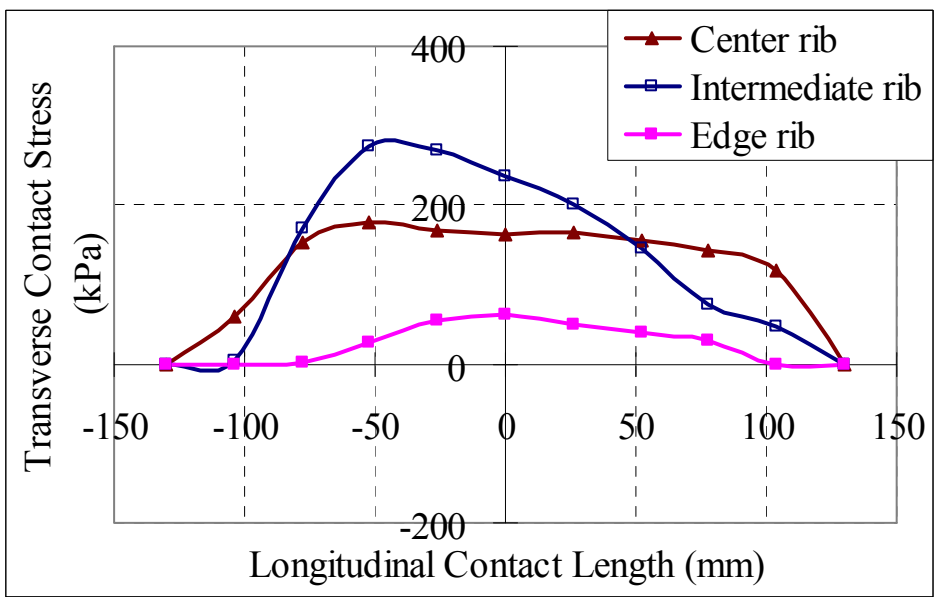

(b)

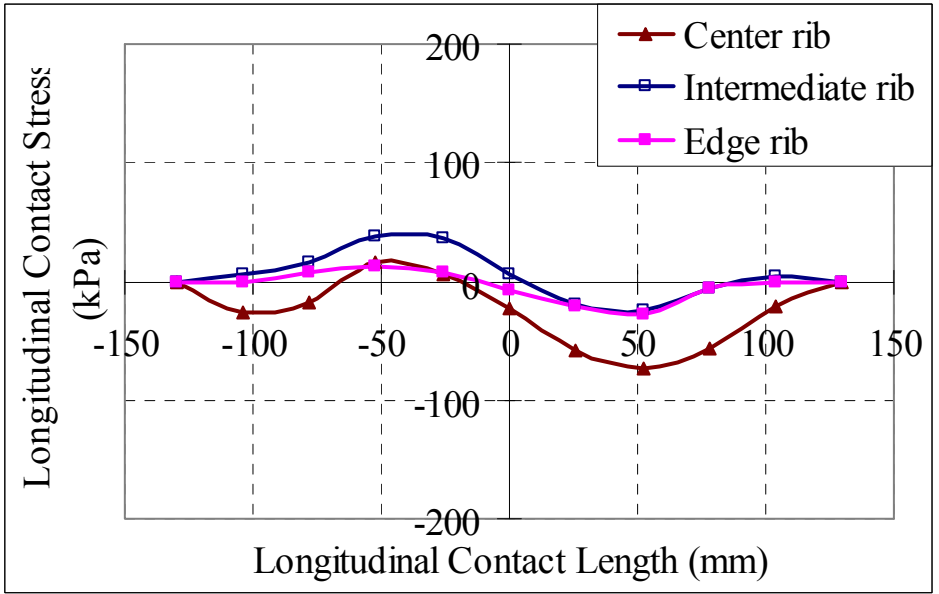

(c)

Fig. 9. Comparison of (a) vertical, (b) transverse, and (c) longitudinal contact stress distributions at cornering condition 


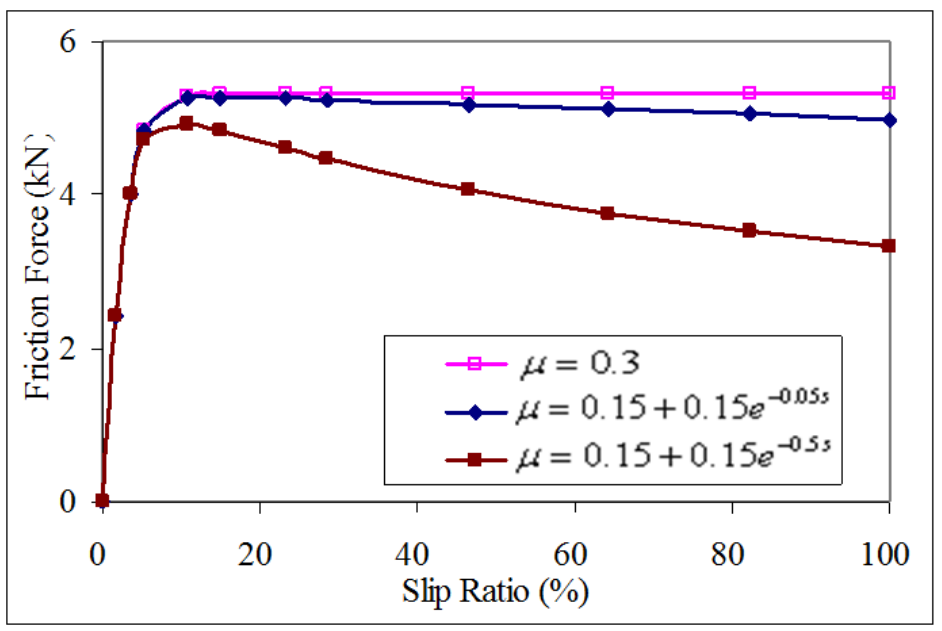

(a)

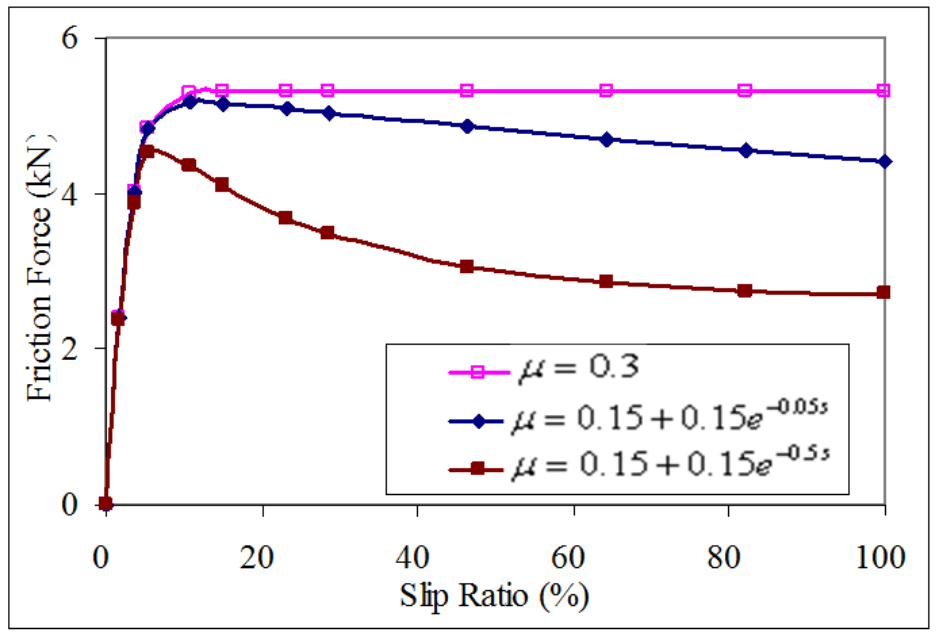

(b)

Fig. 10. Friction forces due to tire braking using different friction models at (a) $10 \mathrm{~km} / \mathrm{h}$ and (b) $30 \mathrm{~km} / \mathrm{h}$

\section{Accepted Manuscript Not Copyedited}




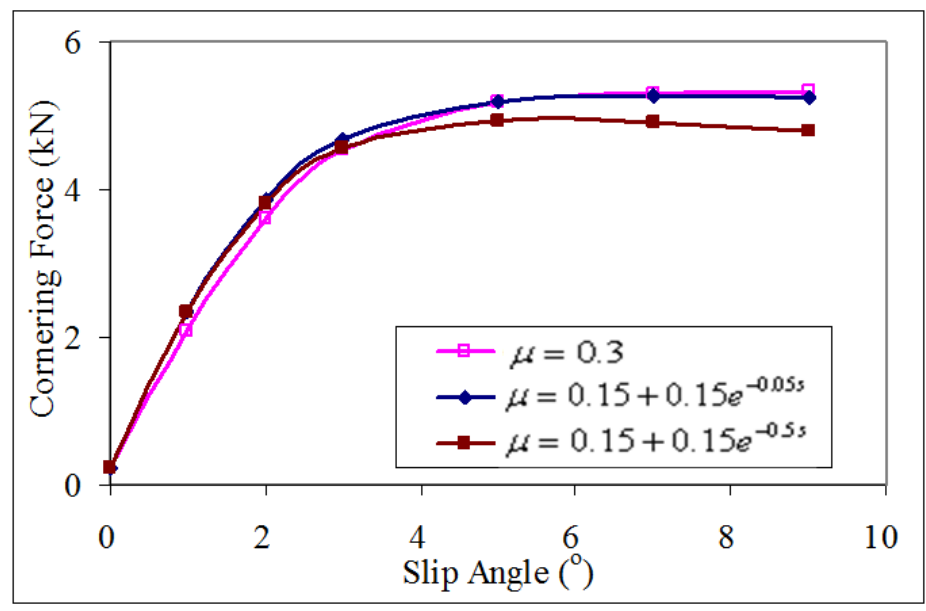

Fig. 11. Cornering forces using different friction models

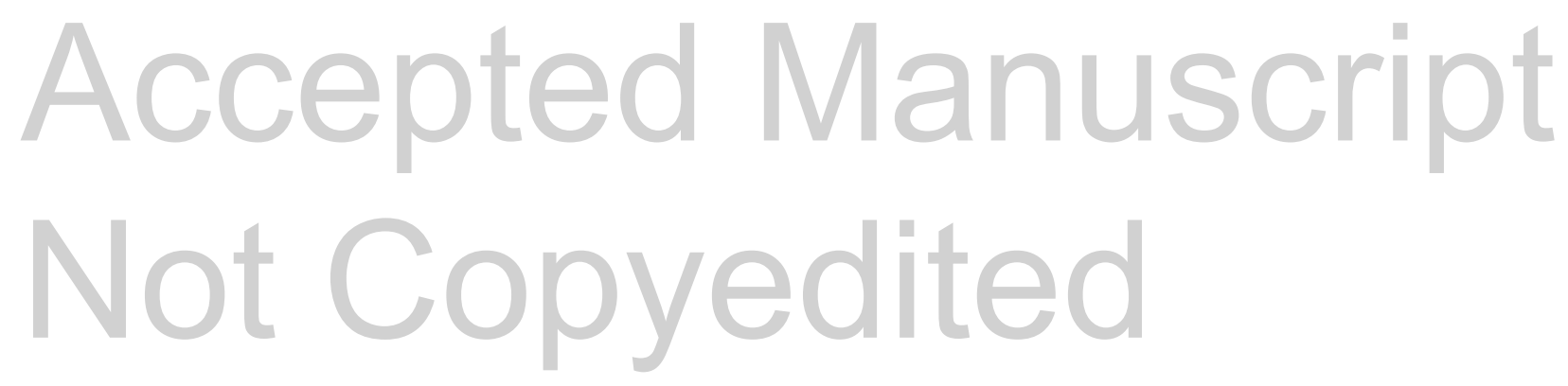


Table 1. Maximum contact stresses with different friction coefficients

\begin{tabular}{|c|c|c|c|c|c|}
\hline \multirow{2}{*}{$\begin{array}{c}\text { Rolling } \\
\text { Condition }\end{array}$} & \multirow{2}{*}{$\begin{array}{c}\text { Friction } \\
\text { Coefficient }\end{array}$} & \multicolumn{2}{|c|}{ Maximum Contact Stresses (MPa) } & Maximum \\
\cline { 3 - 5 } & & Vertical & Transverse & Longitudinal & \\
\hline \multirow{3}{*}{$\begin{array}{c}\text { Free } \\
\text { Rolling }\end{array}$} & $\mu=0.3$ & 1056 & 223 & 65 & $1: 0.21: 0.06$ \\
\cline { 2 - 6 } & $\mu=0.5$ & 1051 & 309 & 73 & $1: 0.29: 0.07$ \\
\cline { 2 - 6 } & $\mu=0.8$ & 1067 & 391 & 81 & $1: 0.37: 0.08$ \\
\hline \multirow{3}{*}{$\begin{array}{c}\text { Full } \\
\text { Braking }\end{array}$} & $\mu=0.3$ & 1053 & 14 & 316 & $1: 0.02: 0.30$ \\
\cline { 2 - 6 } & $\mu=0.5$ & 1099 & 38 & 549 & $1: 0.03: 0.50$ \\
\hline \multirow{2}{*}{$\begin{array}{c}\text { Cornering } \\
\text { (slip angle } \\
\left.=1^{\circ}\right)\end{array}$} & $\mu=0.8$ & 1144 & 73 & 915 & $1: 0.06: 0.80$ \\
\cline { 2 - 6 } & $\mu=0.5$ & 1302 & 401 & 85 & $1: 0.31: 0.07$ \\
\cline { 2 - 5 } & $\mu=0.8$ & 1432 & 485 & 95 & $1: 0.34: 0.07$ \\
\hline
\end{tabular}


Table 2. Maximum contact stresses with different friction models

\begin{tabular}{|c|c|c|c|c|c|}
\hline \multirow{2}{*}{$\begin{array}{l}\text { Rolling } \\
\text { Condition }\end{array}$} & \multirow{2}{*}{ Friction Model } & \multicolumn{3}{|c|}{ Maximum Contact Stresses (MPa) } & \multirow{2}{*}{$\begin{array}{c}\text { Maximum } \\
\text { Stress } \\
\text { Ratio }\end{array}$} \\
\hline & & Vertical & Transverse & Longitudinal & \\
\hline \multirow{3}{*}{$\begin{array}{c}\text { Free } \\
\text { Rolling }\end{array}$} & $\mu=0.3$ & 1056 & 223 & 65 & $1: 0.21: 0.06$ \\
\hline & $\mu=0.15+0.15 e^{-0.05 s}$ & 1056 & 223 & 65 & $1: 0.21: 0.06$ \\
\hline & $\mu=0.15+0.15 e^{-0.5 s}$ & 1056 & 223 & 65 & $1: 0.21: 0.06$ \\
\hline \multirow{3}{*}{$\begin{array}{c}\text { Full } \\
\text { Braking }\end{array}$} & $\mu=0.3$ & 1053 & 19 & 316 & $1: 0.02: 0.30$ \\
\hline & $\mu=0.15+0.15 e^{-0.05 s}$ & 1052 & 14 & 306 & $1: 0.01: 0.29$ \\
\hline & $\mu=0.15+0.15 e^{-0.5 s}$ & 1051 & 10 & 240 & $1: 0.01: 0.23$ \\
\hline \multirow{3}{*}{$\begin{array}{l}\text { Cornering } \\
\quad \text { (slip } \\
\text { angle } \\
\left.=1^{\circ}\right)\end{array}$} & $\mu=0.3$ & 1157 & 277 & 73 & $1: 0.24: 0.06$ \\
\hline & $\mu=0.15+0.15 e^{-0.05 s}$ & 1157 & 276 & 73 & $1: 0.23: 0.06$ \\
\hline & $\mu=0.15+0.15 e^{-0.5 s}$ & 1153 & 272 & 73 & $1: 0.23: 0.06$ \\
\hline
\end{tabular}

